\title{
A Model for Tonsillectomy
}

\author{
${ }^{1}$ Dr. G. Shankar, ${ }^{2}$ Dr. Jugmalram \\ ${ }^{1}$ (Professor \& unit head, department of ENT, vijayanagara institute of medical sciences, Bellary, Karnataka \\ India) \\ ${ }^{2}$ (Postgraduate in ENT, department of ENT, Vijayanagara institute of medical sciences, Bellary, Karnataka \\ India)
}

\begin{abstract}
Tonsillectomy is the most common surgery performed by an ENT surgeon \& it is the most risky surgery as its complications are sometime life threatening. So far not much effort has been focused in training the junior residents in tonsillectomy using the models, like temporal bone dissection for ear surgeries, whereas lot of live ENT surgical workshop are conducted other than tonsillectomy to train junior residents in different ENT surgeries. An attempt has been made to develop the model for tonsillectomy taking into account all the parameters one encounters during tonsillectomy \& train the junior residents with handmade convenient, economical \& practical model. We are successfully training the resident doctors with this model that improves their orientation, surgical skills \& reduces the operating time \& complications of tonsillectomy.
\end{abstract}

Keywords: Tonsillectomy model, VIMS,

\section{Introduction}

Tonsillectomy is a procedure commonly performed by otolaryngologists. Accordingly, there is growing emphasis on the need for ENT surgical trainees to develop competence in tonsillectomy.

Amongst all steps of tonsillectomy, tying the bleeders is an important skill that requires good manual dexterity and one that is difficult to learn under the stress of operating table.

There is a growing need for the use of simulation to practice tonsillectomy to train junior residents. We present a simple, readily available and economical simulation model for surgical trainees to practice tonsillectomy.

\section{Equipment:}

Plastic glass, sponges, cotton balls, plastic sheet, red ink, Temporal bone stand,

\section{Measurement:}

Plastic glass length: $9 \mathrm{~cm}$, height $-7 \mathrm{~cm}$, diameter-7cm

Sponges / cotton balls: length $-4 \mathrm{~cm}$, breath-1.5cm, thickness- $-1.5 \mathrm{~cm}$

\section{Instruments}

Routine tonsillectomy set without draffin's bipod stand \& boyle's Davis mouth gag(figure 1). A plastic glass-measuring $9 \mathrm{~cm}$ length, $7 \mathrm{~cm}$-diameter, $7 \mathrm{~cm}$-height, with both ends open to simulate the oral cavity, sponges (to simulate superior constrictor) are attached on the lateral aspects at $1 \mathrm{~cm}$ from the bottom of the cup. Over the sponges white plastic sheets (to simulate plane of tonsillar bed) are pasted. Over this cotton balls soaked in red ink \& dried are pasted to simulate the tonsils(figure 2-5).

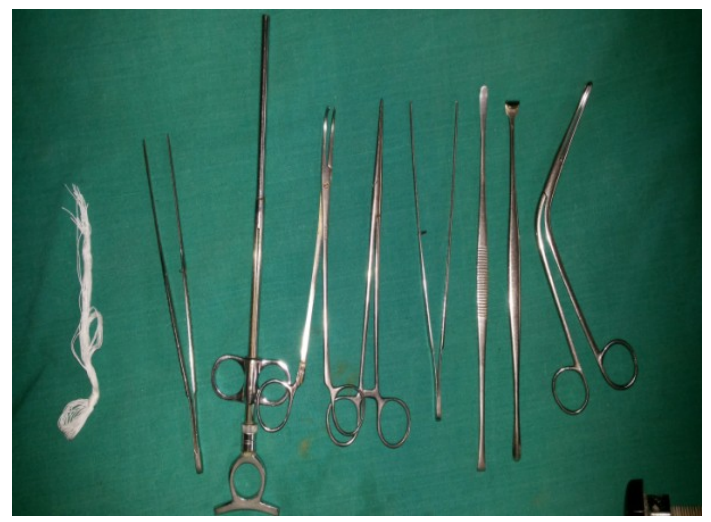

Figure 1- instruments for tonsillectomy 


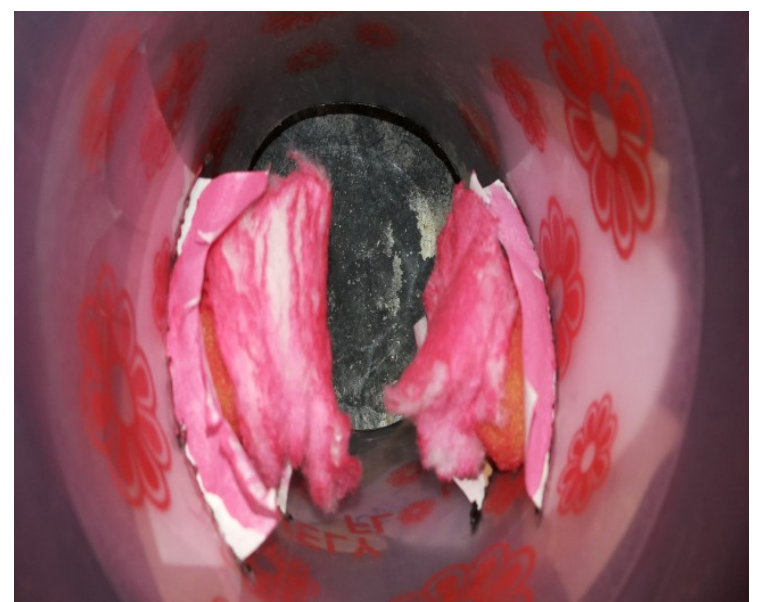

Figure 2- bilateral tonsils with its bed $\&$ pillars

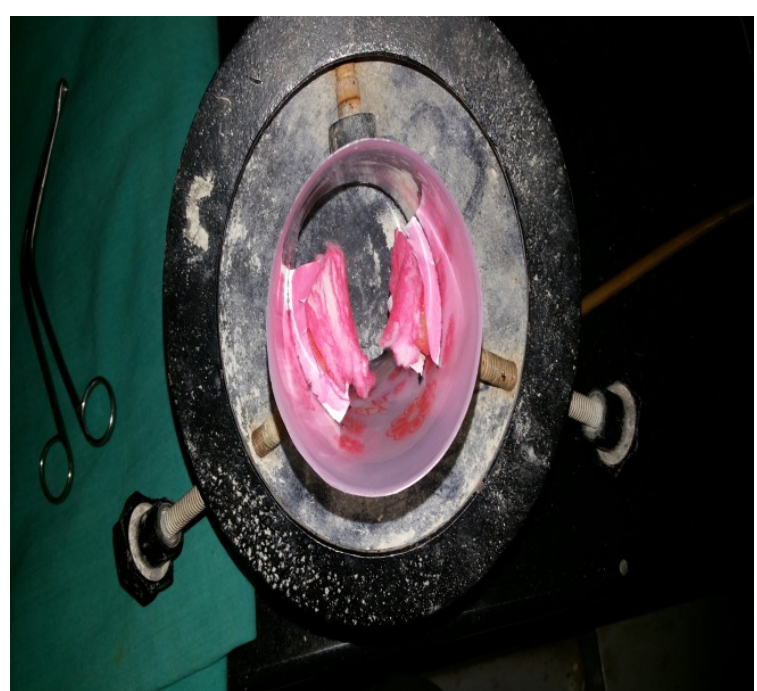

Figure 3- tonsillectomy model on its stand

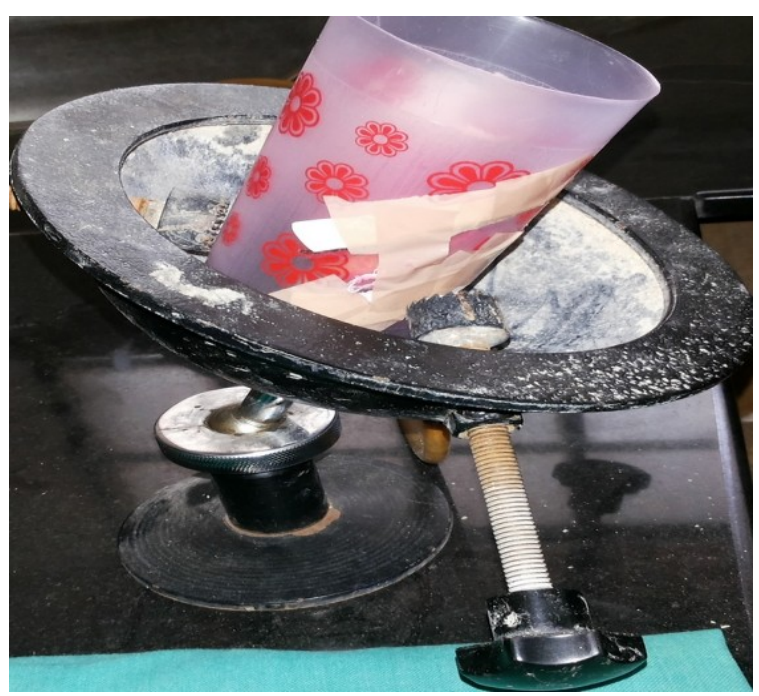

Figure 4- lateral view of model 


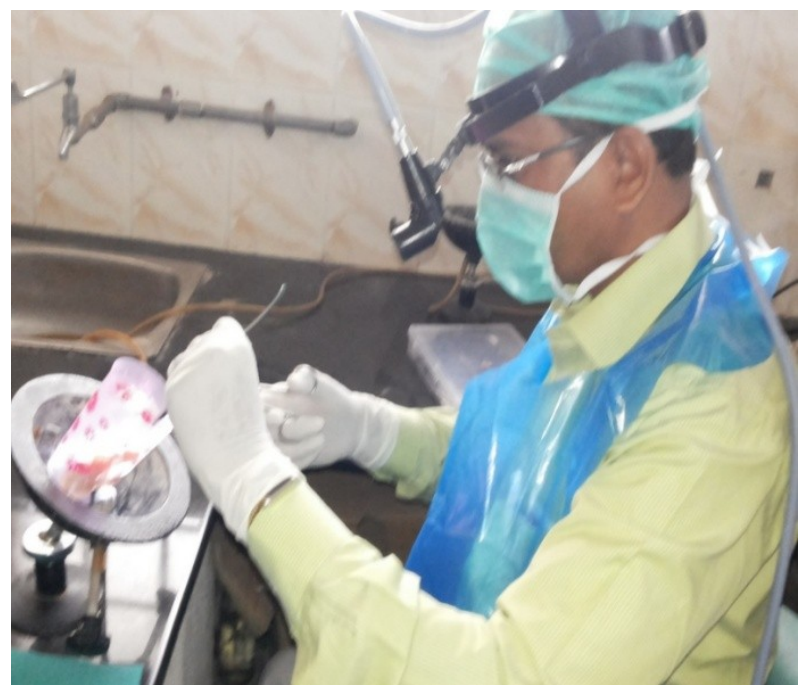

Figure 5- surgeon position during tonsillectomy

III. Procedure:

Tonsillectomy started as usual, the trainee will take same position \& set- up as if in a OT as shown in the below picture. the trainee has to dissect the cotton balls from the bed meticulously(figure 6) \& then practice ligating by catching underlying sponge. Trainee has to put as many knots as possible without sponge being peeled out.

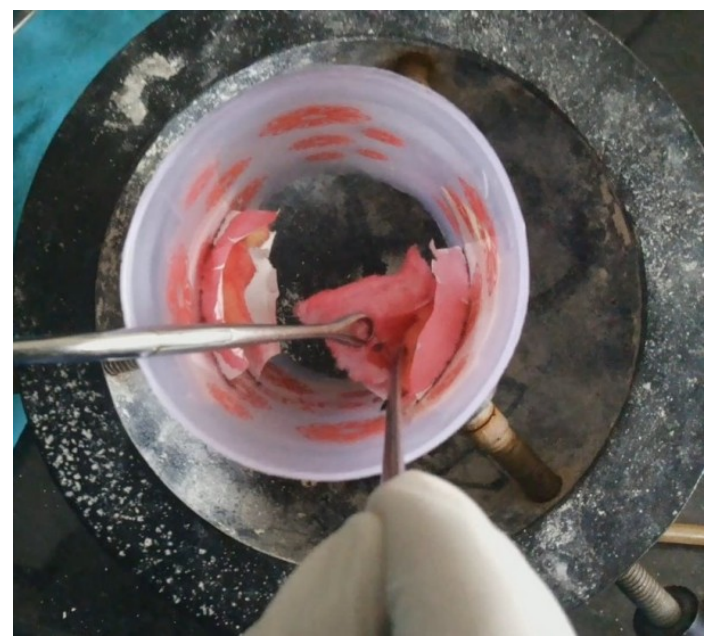

Figure 6 - dissection of tonsillectomy bed

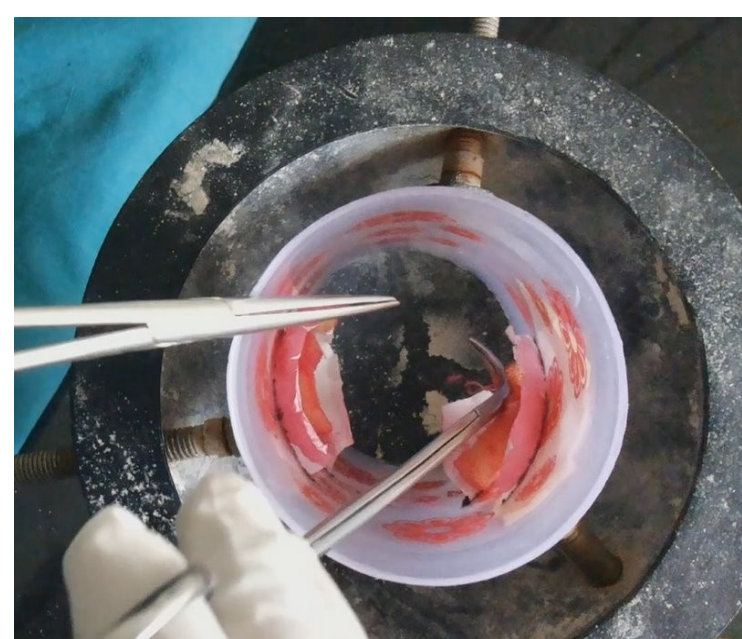

Figure 7- stabilizing the bleeding vessel with second artery 


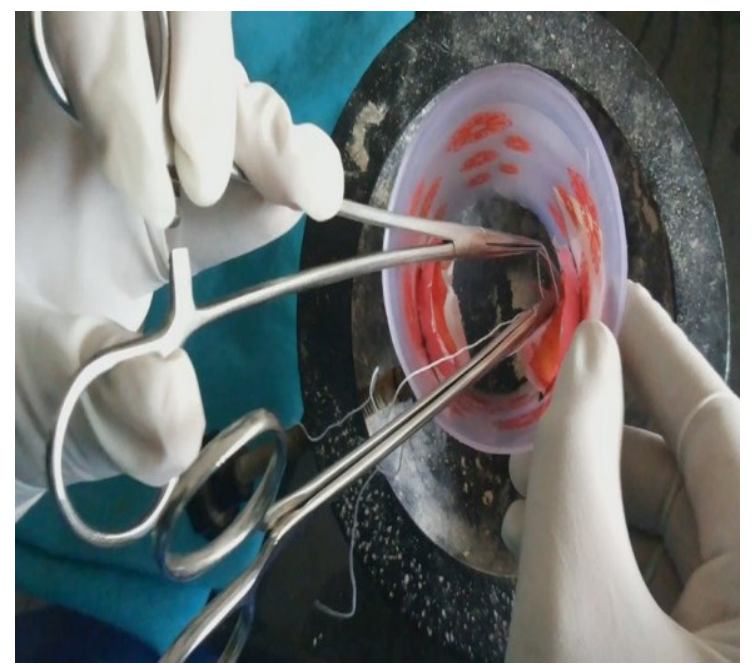

Figure 8-lagation of bleeding vessel

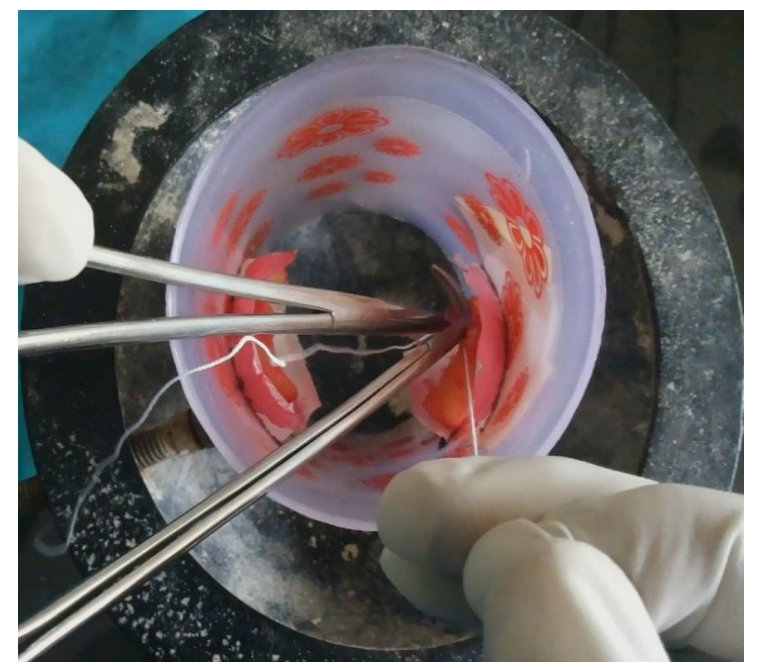

Figure 9- ligation of vessel

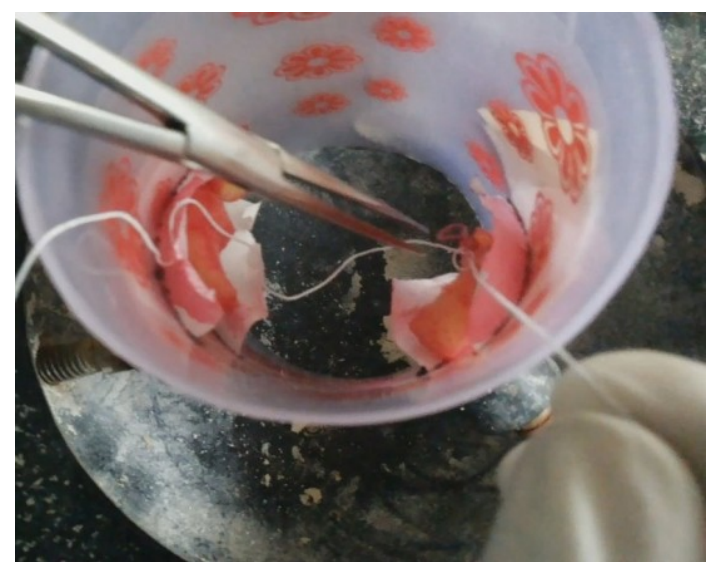

Figure 10- ligation of vessel at inferior pole of tonsil

Our model takes into account as many parameters as possible that one encounters during tonsillectomy, where as currently available costly models focus only on tying the bleeder knots only.

\section{Conclusion}

Given its very basic nature, this model does fully mimic the spatial orientation available during a tonsillectomy. It allows the junior resident to become familiar with tonsillectomy instruments 
and develop the manual dexterity required to apply ligatures in a controlled environment. We hope that otolaryngology trainees may utilize this model as a simple aid to their training.

\section{References}

[1]. Lowe D, van der Mullen J, Cromwell D, et al. (2007) Key messages from the

[2]. National Prospective Tonsillectomy Audit. Laryngoscope 117: 717-724.

[3]. Hall L, Lee M (2011) Training for tonsillectomy: home-made Negus knot pusher.

[4]. Clin. Otolaryngol. 36: 99-100.

[5]. Raja MK, Haneefa MA, Chidambaram A (2008) Yorick's skull model for

[6]. Tonsillectomy ties training. Clin. Otolaryngol. 33: 187-188.

[7]. Street I, Beech T, Jennings C (2006) The Birmingham trainer: a simulator for

[8]. ligating the lower tonsillar pole. Clin. Otolaryngol. 31:79.

Corresponding author for author enquiry and details: Dr.G.Shankar, drshankarent@gmail.com, 